\title{
Polymeric nanoparticles loaded naringin and naringenin: effect of solvent, characterization, photodegradation and stability studies
}

\author{
Leticia M. Cordenonsia ${ }^{a *}$, Rafaela M. Sponchiado ${ }^{a}$, Jardel Rodrigo Bandeira ${ }^{\mathrm{b}}$, Roberto Christ Vianna Santos ${ }^{\mathrm{c}}$, Renata P. \\ Raffin $^{\mathrm{b}}$ and Elfrides E. S. Schapoval ${ }^{\mathrm{a}}$
${ }^{a}$ Programa de Pós-Graduação em Ciências Farmacêuticas, Faculdade de Farmácia, Universidade Federal do Rio Grande do Sul, 90610-000 Porto Alegre - RS, Brasil
${ }^{b}$ Programa de Pós-Graduação em Nanociências, Universidade Franciscana, 97010-032 Santa Maria - RS, Brasil ${ }^{c}$ Microbiology and Parasitology Department, Federal University of Santa Maria, Santa Maria, RS, Brazil

\section{*Corresponding author: leticiacordenonsi@hotmail.com}

\begin{abstract}
Naringin (NAR) and naringenin (NGE) are flavonoids with important effects, such as antioxidant, nephroprotective and anti-inflammatory action. However, factors such as poor solubility and oral bioavailability, gastrointestinal instability and extensive first pass metabolism lead to limited deliverability. As far as we know, there are no papers describing the use of combination of NAR and NGE in nanoparticles. This paper describes the development and characterization of novel nanoparticles containing NAR and NGE (NAR-NGE-NPs) which were prepared by nanoprecipitation using ethanol. Size distribution of NAR-NGE-NPs demonstrated a narrow distribution $(121 \mathrm{~nm})$, low polydispersity $(<0.1)$, and encapsulation efficiencies were greater than 80\%. Infrared spectroscopy analyses confirmed the structure of NAR-NGE-NPs and in transmission electron microscopy, NAR-NGE-NPs presented a spherical and regular shape. A degradation study by UVC, NAR-NGE-NPs improved photostability and conferred protection against NAR and NGE degradation. Minimal inhibitory concentrations of NAR and NGE were evaluated, however samples did not show antimicrobial activity. In this investigation, new NAR-NGE-NPs were successfully developed by a nanoprecipitation technique, using Endragit ${ }^{\circledR}$ L100 as polymer and ethanol as solvent.
\end{abstract}

Keywords: Flavonoids, Naringin, Naringenin, Nanoparticles, Stability. https://doi.org/10.22456/2527-2616.108783

\section{Introduction}

In genus Citrus, some plants have not yet been much studied, as in the case of grapefruit (Citrus maxima). The main flavonoids of grapefruit are naringin (NAR) and its aglycone, naringenin (NGE) [1]. NAR and NGE exert a variety of biological/pharmacological effects such as antioxidant, antiatherogenic, hepatoprotective, nephroprotective and anti-inflammatory [2-4]. In two studies with rats applying streptozotocin induced diabetes, NAR was able to avoid diabetic neurogenic pain by preventing free radical formation and antioxidant activity in the sciatic nerve [5]. In addition, NGE decreased the blood glucose level and improved dyslipidemia [6]. In another study, the treatment of mice for six months with NGE led to a reduction in the progression of atherosclerosis [7]. In rabbits fed with a high cholesterol diet, supplementation of $0.1 \%$ NAR or $0.05 \%$ of NGE for eight weeks decreased aortic fatty streak area when compared to controls [8]. However, the deliverability of NAR and NGE is limited due to its poor aqueous solubility, gastrointestinal instability, extensive first pass metabolism and poor oral bioavailability [9]. Evidence was provided that orally administered NAR was hydrolyzed by enterobacteria to aglycone before absorption and NGE have a rapid distribution and elimination [10]. In such cases, polymeric nanoparticles (NPs) probably minimize these problems, modifying drug delivery profiles, improving stability, increasing solubility and protecting drug against fast metabolism [11]. It is essential to select the polymer appropriately in order to develop successful polymeric NPs. Therefore, methacrylic acid copolymers have been extensively studied, such as Eudragit ${ }^{\circledR}$ L100, resulting from the anionic copolymerization of methacrylic acid and methyl methacrylate, with $\mathrm{pH}$-dependent behavior [12-13].

In the present study, we describe the preparation and extensive optimization of naringin-naringeninnanoparticles (NAR-NGE-NPs) with different solvents. As far as we know, there are no papers describing the combination of NAR and NGE in NPs. The best formulation was characterized in terms of morphology, chemical composition and crystallinity, the photodegradation kinetics and stability studies of NARNGE-NPs were performed. Antibacterial assay by minimal inhibitory concentration (MIC) of NAR and NGE was also assessed.

\section{Experimental section}

\section{Materials}

NAR with $96.6 \%$ purity, NGE with $99.2 \%$ purity and sorbitan monostearate were purchased from SigmaAldrich $^{\circledR}$ (Buchs, Switzerland). Eudragit ${ }^{\circledR}$ L100 and Eudragit ${ }^{\circledR} \quad$ S100 (Methacrylic Acid - Methyl Methacrylate Copolymer) were supplied by Röhm 
Pharma Polymers ${ }^{\circledR}$ (Dramstadt, Germany). Polysorbate 80 and isopropyl adipate were purchased from Via Farma ${ }^{\circledR}$. All solvents were of analytical grade and obtained from various sources and MilliQ ${ }^{\circledR}$ water was used throughout the experiment.

\section{Preparation and optimization of nanoparticles containing naringin and naringenin}

The NPs were prepared according to the method of interfacial deposition of pre-formed polymer (nanoprecipitation) described by Fessi and collaborators with modifications [14]. The organic phase containing the two flavonoids (0.05 $\mathrm{g}$ of each), Eudragit ${ }^{\circledR}$ L100 or Eudragit $^{\circledR} \mathrm{S} 100(0.25 \mathrm{~g})$, sorbitan monostearate $(0.0962$ $\mathrm{g})$, isopropyl adipate $(0.395 \mathrm{~g})$ dissolved in ethanol or mixture of solvents (qsp $100 \mathrm{~mL}$ ) (isopropanol, tetrahydrofuran, acetone) were poured over the aqueous phase containing polysorbate $80(0.385 \mathrm{~g})$. The organic solvent was removed, evaporated until a final volume of $25 \mathrm{~mL}$ and the suspension was stored at room temperature $\left(25 \pm 3{ }^{\circ} \mathrm{C}\right)$. NAR and NGE-free NPs were prepared following the same procedure as for NAR-NGE-NPs. The preparation of NAR-NGE-NPs was optimized to obtain a final formulation with adequate macroscopic analysis, small particle size $(<200 \mathrm{~nm})$, low polydispersity index $(\mathrm{PdI}<0.2)$ and large zeta-potential.

\section{Characterization of nanoparticles}

Determination of the particle size, polydispersity index and zeta-potential

The determination of particle size and polydispersity index (PdI) of the NAR-NGE-NPs was performed in triplicate by dynamic light scattering (Zetasizer ${ }^{\circledR}$, model ZEN 3600, Malvern) after 500-fold dilution (v/v) in water. The zeta-potential was obtained by electrophoresis (Zetasizer ${ }^{\circledR}$, model ZEN 3600, Malvern), after 500-fold dilution (v/v) in $\mathrm{NaCl} 10 \mathrm{mM}$.

\section{Determination of naringin and naringenin concentration and encapsulation efficiencies}

The concentration and encapsulation efficiencies were determined using the stability-indicating high-pressure liquid chromatography (HPLC) method, previously validated as described by Cordenonsi and co-workers [15]. Successful resolution and retention times were obtained with a Zorbax Eclipse Plus C18 column (4.6 mm x $150 \mathrm{~mm}, 5 \mu \mathrm{m})$ at a temperature of $25^{\circ} \mathrm{C}$, at a $1 \mathrm{~mL}$ min-1 flow rate, $285 \mathrm{~nm}$ wavelength and the injection volume was $20 \mu \mathrm{l}$. Ultrapure water (A) with $\mathrm{pH}$ 4.0, adjusted with hydrochloric acid $0.1 \mathrm{M}$ and acetonitrile (B) were used to prepare the mobile phase. Separation was performed using gradient elution: 0-4 min 10\%-70\% B 4$5 \min 70-100 \%$ B 5-6 min 100-70\% B 6-8 $\min 70-10 \%$ B. At the interval between each run, the system remained under a stabilization process for three minutes. The stock solution was prepared with ethanol and the dilutions were done with water at pH 4.0 and acetonitrile (1:1) (v/v). The method was linear in the range of $1.0-40.0 \mu \mathrm{g} \mathrm{mL}-1$ for both NAR and NGE ( $r>0.99)$ with adequate results for precision $(<0.9 \%)$ and accuracy $(98.8 \%)$. Limits of detection and quantification were $0.11 ; 0.38 \mu \mathrm{g} \mathrm{mL}^{-1}$ and $0.35 ; 0.90 \mu \mathrm{g} \mathrm{mL}-1$ for NAR and NGE, respectively. The specificity of the method and its stability indicating capability were demonstrated through forced degradation studies, which showed that there was no interference from the excipients. The Plackett-Burman experimental design was used to evaluate robustness producing results within the acceptable range.

NAR and NGE were determined in the ultrafiltrate after separation of the NAR-NGE-NPs suspension by ultrafiltration-centrifugation technique. The total content of NAR and NGE in the suspension was determined using HPLC after dissolution in acetonitrile. The associated NAR and NGE with the NPs suspension were calculated from the difference between the total and the free drug concentrations determined in the NPs suspension and in the ultrafiltrate, respectively. The HPLC (Agilent ${ }^{\circledR} 1200$ series, Santa Clara, USA) was equipped with a quaternary pump, auto-injector, compartment with thermostat, photodiodes array detector and degasser.

\section{Viscosity measurements}

The viscosity of NAR-NGE-NPs suspension was measured at $25 \pm 1{ }^{\circ} \mathrm{C}$ using a rotational viscometer (LVDV II+ Pro model, Brookfield, USA) equipped with SC4-25 spindle and a small sample adapter.

\section{Transmission electron microscopy}

Surface morphology of NAR-NGE-NPs and control-NPs were evaluated by transmission electron microscopy (TEM) (JEM 1200EX II) operated at $120 \mathrm{kV}$. For this analysis, the diluted suspensions with water $(1: 10)$ were deposited on a specimen grid (Formvar-Carbon support film, Electron Microscopy Sciences) and stained with uranyl acetate solution $(2 \% \mathrm{w} / \mathrm{v})$ for 1 minute.

\section{Infrared spectroscopy}

The molecular characteristics of NAR, NGE, NAR-NGENPs and Eudragit ${ }^{\circledR}$ L100 were subjected to infrared spectra (IR), on Shimadzu ${ }^{\circledR}$ (model 8001). The spectra were obtained via the Attenuated Total Reflection (ATR) method in a frequency range of 4,000-600 $\mathrm{cm}^{-1}$.

\section{Differential scanning calorimetry}

The physical state of NAR, NGE, NAR-NGE-NPs and control-NPs was analyzed using a differential scanning calorimeter (DSC) Shimadzu (Shimadzu, Kyoto, Japan), model DSC-60, with flow controller FC-60, integrator 60 WS and software TA 60 (version 2.0). Samples were sealed into aluminum pans and heated at a rate of $10^{\circ} \mathrm{C}$ min-1, under nitrogen atmosphere. 


\section{Forced degradation and stability studies}

For forced degradation, aliquots of NAR-NGE-NPs were transferred to a $1 \mathrm{~cm}$ quartz cell (triplicate) and exposed in a mirror chamber $(100 \times 18 \times 17 \mathrm{~cm})$, horizontally positioned in order to have the maximum exposure area, under the direct incidence of UV-C radiation (Light Express lamp LE UV $(254 \mathrm{~nm} / 30 \mathrm{~W})$. The temperature was controlled in the chamber at around $25^{\circ} \mathrm{C}$. Samples were exposed from 1 to 120 hours. After the period in the chamber, the samples were analyzed by HPLC under the conditions described above. A control sample was wrapped in foil and introduced into the chamber for the same time intervals. In stability studies, NAR-NGE-NPs were stored at room temperature $\left(25{ }^{\circ} \mathrm{C} \pm 3{ }^{\circ} \mathrm{C}\right)$, refrigerator temperature $\left(5^{\circ} \mathrm{C}-8^{\circ} \mathrm{C}\right), 40^{\circ} \mathrm{C}$ and $60^{\circ} \mathrm{C}$ for 60 days. Aliquots were withdrawn at scheduled times and analyzed in terms of macroscopic analysis, average concentration of both flavonoids, $\mathrm{pH}$ and particle size.

\section{Photodegradation kinetics of nanoparticles containing naringin and naringenin}

The samples were prepared as described in the forced degradation study. The degradation order was determined by plotting the graph of concentration versus time (zero order), logarithm of concentration versus time (first order) and inverse concentration versus time (second order). Degradation rate constant $(\mathrm{k})$ and $\mathrm{t}_{1 / 2}$ were calculated after determining the order of the reaction [16-17].

\section{Antibacterial assay}

NAR and NGE were dissolved in dimethyl sulfoxide (DMSO) at a final concentration of $2.0 \mu \mathrm{g} \mathrm{mL}-1$ of each flavonoid. According to the microdilution method published by the Clinical and Laboratory Standards Institute [18], the MIC of NAR and NGE were determined in Mueller-Hinton broth (Difco) against standard ATCC (American type culture collection) and isolated (clinical isolate and environment isolate) cultures. The following bacteria were used: Enterococcus faecalis (ATCC 29212), Streptococcus sp, Listeria monocytogenes (ATCC 7644), Klebsiella pneumonia (ATCC 700603), Escherichia coli (ATCC 25922), Shigella flexneri (ATCC 12022323A), Salmonella enteritidis, Providencia rettgeri (ATCC 2994), Proteus mirabilis (ATCC 25933), Morganella morganii (ATCC 8019), Enterobacter aerogenes (ATCC 13048), Enterococcus faecium (ATCC 6569), Acinetobacter baumannii (ATCC 19606), Staphylococcus epidermidis (ATCC 35985), Paenibacillus larvae (ATCC 9535), Paenibacillus borealis, Paenibacillus thianinolyticus, Paenibacillus gluconolupticus, Paenibacillus seginolipticus, Paenibacillus pabuli, Paenibacillus apiarus, Paenibacillus azotofixans, Paenibacillus validus, Citrobacter freundii (ATCC 8090).

\section{Statistical analysis}

Data were analyzed by one-way ANOVA with the posthoc Tukey test. A value of $p<0.05$ was considered to be statistically significant.

\section{Results and Discussion}

\section{Determination of solvent}

The characteristics of the NPs depend on various manufacturing parameters as polymer, organic solvents, type and concentration of stabilizer. Thus, the choice of the solvent is critical for the success of the method. Several parameters should be considered when choosing a solvent for making NPs, like physical properties of the solvents, ability to dissolve the polymer, drug, and toxicity since there will always be trace amounts of solvent in the final formulation [19]. Some authors report that the physical properties of the organic solvents strongly influence the NPs preparations and the particle size, since particle formation depends on interfacial tension, viscosity of the solvent, solution dielectric constant and solubility of the monomer/polymer [20-22]. For each solvent and mixture of solvents, NAR-NGE-NPs were prepared aiming at NPs with desired particle size $(<200 \mathrm{~nm})$, PdI $(<0.2)$ and large zeta-potential. Table 1 shows the effect of different solvents on the particle sizes, PdI and zeta-potential of NAR-NGE-NPs. Two different polymers were tested maintaining the same concentrations of the other constituents of formulations.

The viscosity of the oil phase, containing the solvent, is an important factor in the preparation of NPs [23]. The size of NPs depends on the oil phase viscosity; the lower the viscosity, the smaller the mean diameter [24]. After preparation, the particle size and PdI were less than 200 nm and 0.2 , respectively, except batch 4 , which was nanometric but larger particles were formed. The smallest particles were obtained using ethanol and ethanol: acetone (1:1) (Batch 1, 6 and 8). These three batches were stored at room temperature $\left(25^{\circ} \mathrm{C} \pm 3{ }^{\circ} \mathrm{C}\right)$ and monitored to observe possible changes in color, appearance of precipitates or sedimentation. After 3 weeks, Batches 6 and 8 changed color and some sedimentation was visible. After that, Batch 1 was selected for characterization and stability studies. Likewise, Galindo-Rodriguez [25] reported a study with five different solvents: ethanol, acetone, DMSO, isopropyl alcohol and ethyl lactate using methacrylic acid copolymer. Ethanol showed the smallest particle size $(79 \mathrm{~nm})$, followed by DMSO $(97 \mathrm{~nm})$, isopropyl alcohol $(101 \mathrm{~nm})$, acetone $(146 \mathrm{~nm})$ and ethyl lactate $(178 \mathrm{~nm})$. 
Table 1. Effect of various solvents and two polymers on particle size, PdI and zeta-potential.

\begin{tabular}{clccc}
\hline Batch & Solvent and proportions & Particle size (nm) & PdI & Zeta-potential (mV) \\
\hline $\mathbf{1}$ & & Eudragit $^{\circledR}$ L 100 & & -16.60 \\
$\mathbf{2}$ & EtOH & 121.0 & 0.096 & -21.90 \\
$\mathbf{3}$ & EtOH: Isopropanol (1:1) & 145.8 & 0.151 & -12.80 \\
$\mathbf{4}$ & EtOH: Isopropanol (2:1) & 106.6 & 0.186 & -26.23 \\
$\mathbf{5}$ & EtOH: THF (1:1) & 230.1 & 0.269 & -10.90 \\
$\mathbf{6}$ & EtOH: THF (2:1) & 121.3 & -16.16 \\
$\mathbf{7}$ & EtOH: acetone (1:1) & 89.3 & 0.025 & -15.90 \\
\hline $\mathbf{8}$ & EtOH: acetone (2:1) & 129.5 & 0.099 & -9.40 \\
\hline
\end{tabular}

EtOH - Ethanol; THF - Tetrahydrofuran

\section{Characterization of optimal suspension of nanoparticles}

Figure 1 shows the chromatograms containing NAR (1c), NGE (1d), NAR-NGE-NPs (1a and 1b) and excipients (1e). A simple, sensitive, precise and linear method by HPLC was established for simultaneous determination and quantification of NAR and NGE in polymeric NPs. The method results in excellent separation in less than 8 min, with a peak purity and the excipients did not interfere in quantification [15].

The method was validated in compliance with guidelines, and was found to be linear in the $1-40 \mu \mathrm{g} \mathrm{mL}-1$ concentration range for both NAR and NGE ( $r>0.99$ ). Repeatability was determined at three concentration levels, obtaining an RSD (\%) $<0.9 \%$, and the accuracy of the method was $>98 \%$ [15].

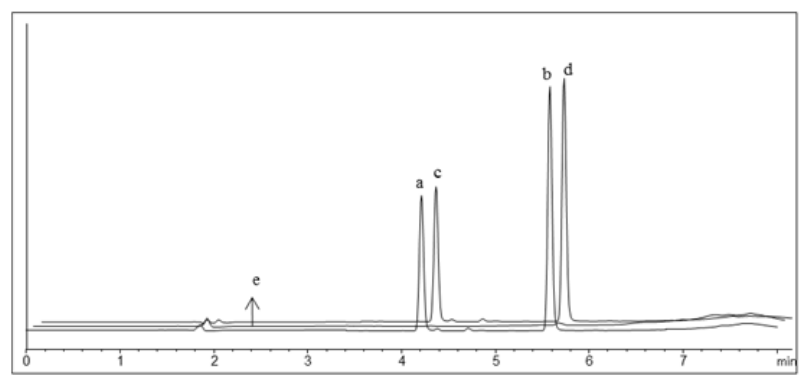

Figure 1. The HPLC chromatograms of nanoparticles of naringin (a), naringenin (b), naringin (c) and naringenin solutions (d) and excipients (e).

NAR-NGE-NPs were prepared by a well-reported interfacial deposition of pre-formed polymer method. This method is a simple, reproducible process to prepare nanocapsules [26]. Ethanol was the best solvent for this study; the visual appearance of the suspension was free of aggregates and displayed the Tyndall effect. Particle size has a crucial impact on the in vivo fate of the particulate drug delivery system and size control is very important for drug carriers [27]. The size distribution of NAR-NGENPs demonstrated a narrow distribution and the PdI lower than 0.1 was identified. The small PdI values indicated a homogeneous dispersion.
The particle size of the formulation without flavonoids was $111.60 \mathrm{~nm}(\mathrm{PdI}=0.159)$, demonstrating that the addition of NAR, and NGE in the formulations did not affect the mean diameter.

No significant $(p>0.05)$ variation was verified when comparing the particle size of NAR-NGE-NPs and control NPs. These values are in agreement with the particle size observed for nanocapsules prepared using the same method [26].

Zeta-potential values are indicators of surface charge, which determines particle stability in dispersion. No significant $(p>0.05)$ variation was observed when comparing the zeta-potential of NAR-NGE-NPs (-16.60 \pm $0.08 \mathrm{mV})$ and control-NPs $(-19.70 \pm 0.03 \mathrm{mV})$. All formulations were negatively charged with a zetapotential because of the terminal carboxyl groups of the anionic polymer Eudragit ${ }^{\circledR}$ L100. The total content in the suspension was $92.15 \pm 0.79 \%$ and $90.34 \pm 0.84$ for NAR and NGE, respectively. High encapsulation efficiencies were found for NAR $(80.90 \%)$ and NGE $(81.34 \%)$. The low viscosity (similar to water) of NAR-NGE-NPs was found to be $1.44 \mathrm{Cp}$. The viscosity similar to water demonstrated that the NPs did not influence the viscosity of the suspension [23].

\section{Transmission electron microscopy}

TEM is a qualitative method used to study the structural aspects of materials [28]. The morphological characteristics of NAR-NGE-NPs and control NPs were investigated. The NPs prepared with Eudragit ${ }^{\circledR}$ L100 showed particles that are regular-shaped and spherical (Figure 2).

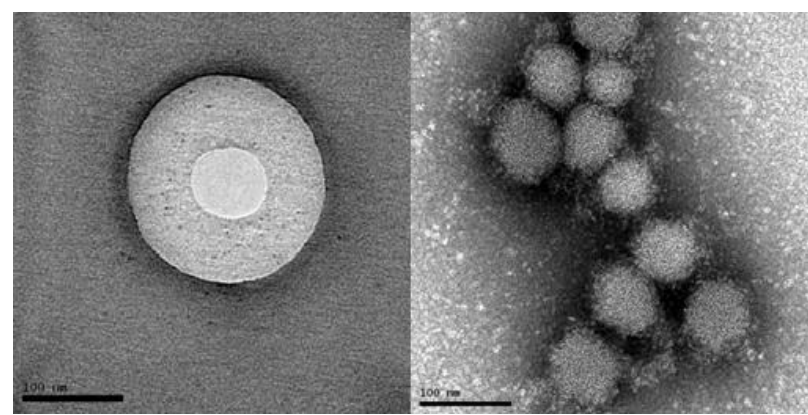

Fig 2. TEM images of NAR-NGE-NPs $(500,000 \mathrm{x})$ and control NPs $(300,000 \mathrm{x})$. 


\section{Infrared spectroscopy}

IR was performed by order to characterize the interactions between the polymer Eudragit ${ }^{\circledR}$ L100 and NAR-NGENPs (Figure 3). The spectra of NAR and NGE (3a and 3b) showed their characteristic bands [29] and spectra of Eudragit ${ }^{\circledR} \mathrm{L} 100$ (3c) showed bands of the $\mathrm{C}=\mathrm{O}$ vibrations of the carboxylic acid groups at $1,700 \mathrm{~cm}^{-1}$.

A band detected between 2,500-3,500 cm-1 and 2,900 $3,000 \mathrm{~cm}-1$ can be attributed to the associated $\mathrm{OH}$ groups and $\mathrm{CHx}$ vibrations, respectively [13]. The formation of the complex between NAR and NGE with Eudragit ${ }^{\circledR}$ L100 was confirmed by IR analyses, because no new chemical bond was formed after preparing the formulation and the results confirmed that the flavonoids are physically dispersed in the polymer Eudragit ${ }^{\circledR}$ L100.

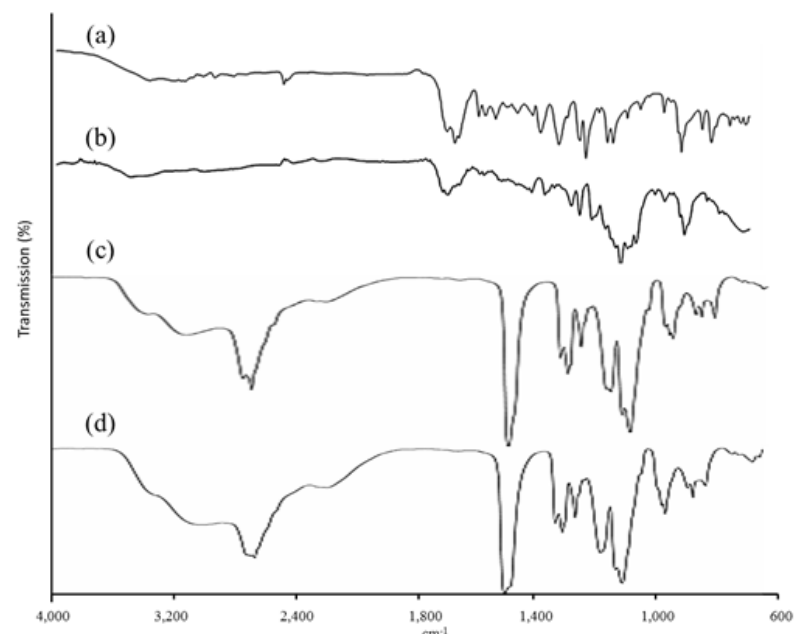

Figure 3. IR spectra of NAR (a), NGE (b), Eudragit ${ }^{\circledR}$ L 100 (c) and NAR-NGE-NPs (d).

\section{Differential scanning calorimetry}

The DSC profile of NAR, NGE, control-NPs, NAR-NGENPs stored at $60{ }^{\circ} \mathrm{C}$ and at room temperature $\left(25^{\circ} \mathrm{C} \pm 3\right.$ ${ }^{\circ} \mathrm{C}$ ) are shown in Figure 4. The DSC profile of NAR (4a) did not show a defined melting point, this may be occurring because NAR is an amorphous structure and does not have a melting point [30]. For NGE the fusion temperature was $252.61{ }^{\circ} \mathrm{C}$. This shows an endothermal event which is represented by descending signals and the result is expressed by a negative value of the differential signal, corroborating data from the literature [9, 31-33]. In Figures $4 \mathrm{c}, 4 \mathrm{~d}$ and $4 \mathrm{e}$, the thermograms presented melting peaks at $40-43^{\circ} \mathrm{C}$, including the control NPs. Based on the melting points of the components, we can suggest that sorbitan monostearate that has a melting point of around $60{ }^{\circ} \mathrm{C}$ melted during the storage at $60^{\circ} \mathrm{C}$ and was responsible for the degradation of the nanostructures at this temperature. The shift of the melting point can be attributed to the nano size and presence of polymer, oil and surfactant in the structure. Absence of new peaks suggested that no chemical interactions occurred between Eudragit and the flavonoids and confirmed that both flavonoids were well encapsulated in the polymeric matrices, as previously shown by the techniques TEM (Figure 2) and IF analyses (Figure 3).

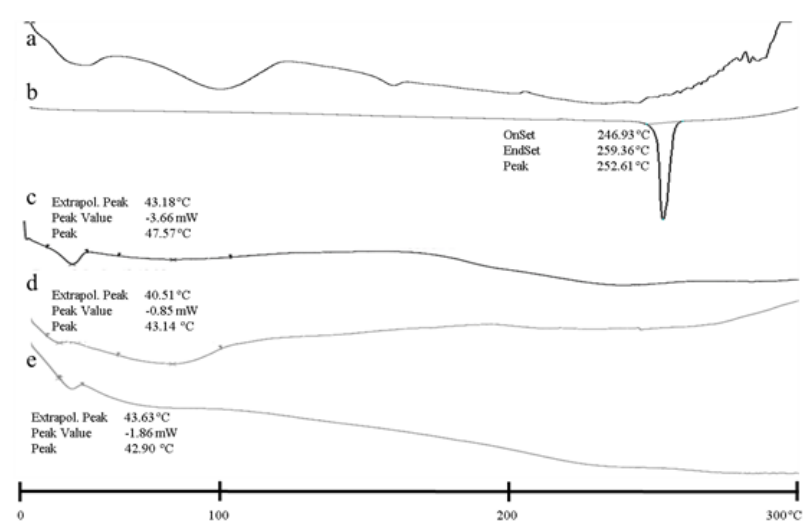

Figure 4. Heating curve obtained by DSC from NAR (4a), NGE (4b), control-NPs (4c), NAR-NGE-NPs stored at $60^{\circ} \mathrm{C}(4 \mathrm{~d})$ and at room temperature $\left(25^{\circ} \mathrm{C} \pm 3{ }^{\circ} \mathrm{C}\right)(4 \mathrm{e})$.

\section{Forced degradation and stability studies}

Photodegradation is an important indicator of chemical stability. UV-C radiation has high energy, and it can be the cause of many oxidation reactions or breakage of weak chemical bonds. These phenomena are energyrelated and, thus, are preceded by photons with specified wavelength [34]. In forced degradation, the degradation profile caused by UV-C revealed that NAR degraded $12 \%$ and NGE about $6 \%$ in 76 hours (Figure 5). Comparing the results, when NAR and NGE were not encapsulated, in 48 hours, NAR degraded $50 \%$ and NGE about $60 \%$. The polymer matrix of NPs can contribute to the improved stability by NAR and NGE. A similar study on structural stability of coenzyme Q10 loaded within poly (methyl methacrylate) showed that both UV induced drug inactivation were effectively hindered when the drug was encapsulated within the polymer nanoparticles [35].

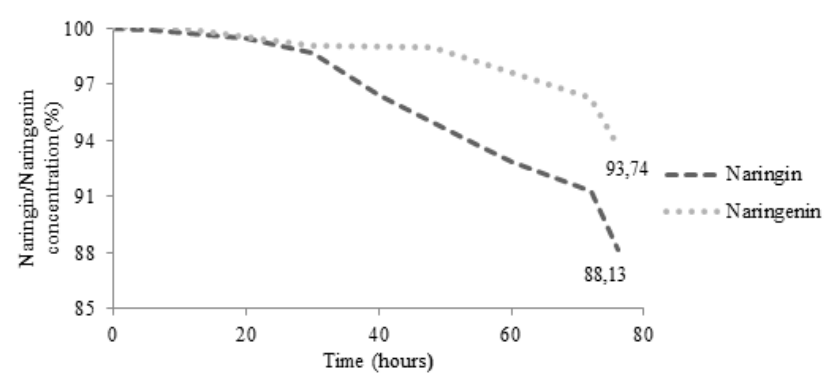

Figure 5. Profile of degradation by UV-C

Nanocapsule composition, preparation method and storage conditions may affect the stability of nanoencapsulated systems [36]. For the stability studies, all formulations were stable as colloidal suspensions without visible creaming, sedimentation, precipitates, flocculation or phase separation. NAR-NGE-NPs stored at room temperature and freezer and control-NPs retained the white color. Formulations subjected to higher temperatures, $40{ }^{\circ} \mathrm{C}$ and $60{ }^{\circ} \mathrm{C}$, had a slight change in color from white to light yellow. The total content of NAR and NGE in NPs during stability studies is shown in 
Figure 6a and 6b. NGE-NPs was more stable than NARNPs. NPs were able to confer protection against the NAR and NGE degradation, and it became evident that room

(a)

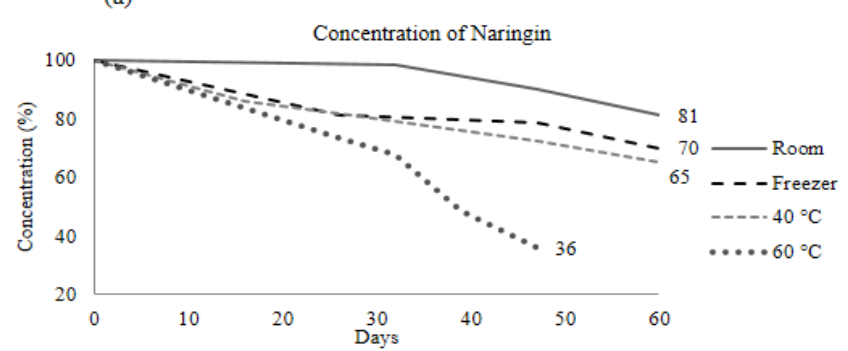

(b)

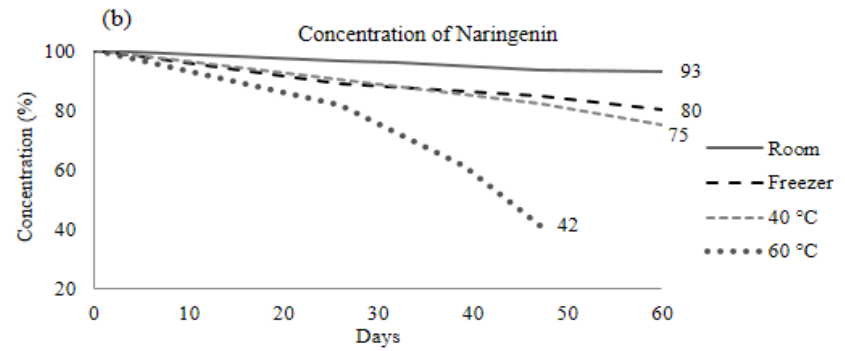

temperature $\left(25^{\circ} \mathrm{C} \pm 3{ }^{\circ} \mathrm{C}\right)$ was the most suitable for maintaining NPs stability.

(c)
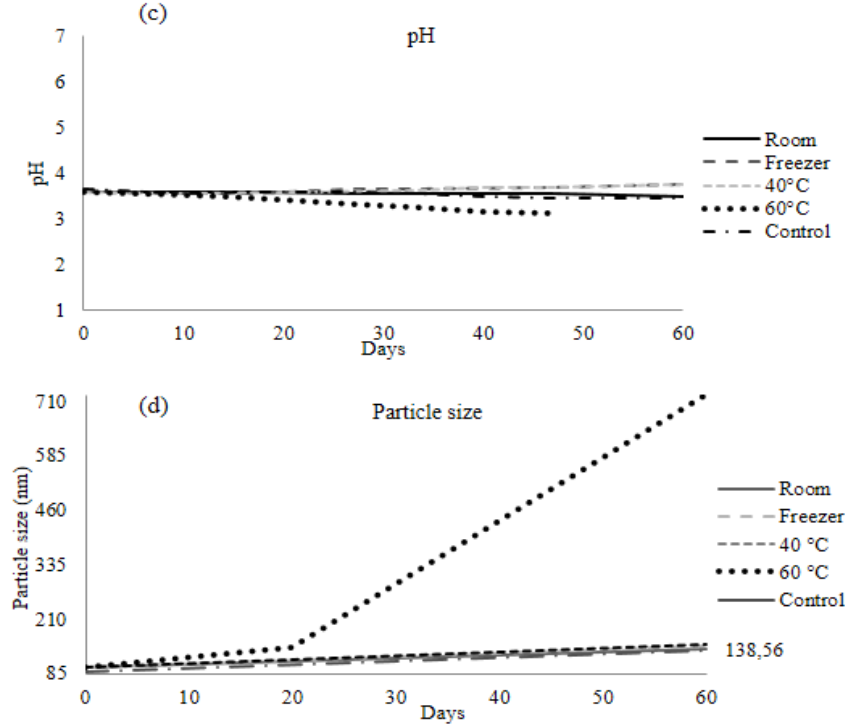

Figure 6. Monitoring NAR-NGE-NPs concentration (a) and (b), monitoring $\mathrm{pH}$ of the suspensions (c) and monitoring particle size of NAR-NGE-NPs (d).

The monitored $\mathrm{pH}$ of the suspensions provides an important indicator of stability. In general, the $\mathrm{pH}$ values of nanocapsule dispersions fall within a range of 3.0-7.5 when produced by nanoprecipitation [36]. This acid character of the suspensions can be explained by the presence of terminal carboxyl groups of the anionic polymer chains [13]. The pH of NAR-NGE-NPs (Figure $6 \mathrm{c})$ and control-NPs remained acid and, when analyzed statistically by ANOVA and Tukey test, showed that there was a change only when exposed to a temperature of $60{ }^{\circ} \mathrm{C}$. The decrease of $\mathrm{pH}$ may be due to partial degradation of Eudragit ${ }^{\circledR}$ L100, oxidation of any constituent or diffusion of the NAR or NGE formulation of the nanocapsules to the aqueous phase. Another possibility may be linked to sorbitan monostearate, which has a melting point of around $60^{\circ} \mathrm{C}$. However, no sign of physical-chemical instability were observed in formulations. The data on the monitoring of the particle size of NAR-NGE-NPs during 60 days are represented in Figure $6 \mathrm{~d}$. When analyzed statistically by ANOVA and Tukey, the values showed that there was a change only when exposed to a temperature of $60{ }^{\circ} \mathrm{C}$, suggesting that the melt of sorbitan monostearate occurred within the core of NPs. Pohlmann and collaborators [37] prepared a different NPs formulation: the NPs were composed only of the polymer, omitting the sorbitan monostearate. For NPs, the sorbitan monostearate would act as an impurity affecting the crystallinity of the polymer. And there are others sources of nanoparticle instability, the aggregation, Ostwald ripening and recrystallization, may lead to forming large particles [38]. Ostwald ripening is the effect by which small particles are essentially consumed by large particles during the growth process, since the small particles have a higher solubility than the large particles [39].

\section{Kinetics of photodegradation of nanoparticles}

The kinetics of photodegradation of NAR-NGE-NPs was calculated by the concentration of NAR and NGE within time. The coefficient that best represents photodegradation kinetics for NAR was zero order kinetics ( $r=0.9960)$, demonstrating that the reaction velocity was independent of the active concentration, with $\mathrm{k}$ of $0.03 \mu \mathrm{g} /$ hour and $\mathrm{t}_{1 / 2}$ was 166.67 hour. NGE presented a second order kinetics $(\mathrm{r}=0.9718)$, the reaction rate depends on two reagents; the value found for $\mathrm{k}$ found was $0.0021 \mu \mathrm{g} / \mathrm{hour}$ and $\mathrm{t} 1 / 2$ was 47.61 hour.

\section{Antibacterial assay}

NGE did not present any inhibitory effect over the different strains and the presence of glycosides in NAR did not enhance antimicrobial activity. This result agrees with that reported by Céliz and collaborators [40], who studied the antimicrobial activity of NAR, NGE and prunin at a concentration of $0.25 \mathrm{mM}$. In another study, NGE was evaluated for the capacity to reduce the production of quorum sensing-controlled factors in the opportunistic pathogen Pseudomonas aeruginosa. The authors found a significant reduction of the production of pyocyanin and elastase in P. aeruginosa without affecting bacterial growth. The authors emphasized a role as inhibitors of the virulence of pathogenic bacteria by interfering with quorum sensing mechanisms [41].

\section{Conclusions}

In this study, novel NAR-NGE-NPs were successfully developed by a nanoprecipitation technique, using 
Eudragit ${ }^{\circledR}$ L100 as polymer and ethanol as solvent. A formulation appeared macroscopically homogeneous, and the nanometric size had a narrow distribution. IR analyses confirmed the structure of NAR-NGE-NPs and demonstrated the formation of a complex between NAR and NGE with Eudragit ${ }^{\circledR}$ L100. The NAR-NGE-NPs presented as spherical and regular shaped in the TEM images. Study by UV-C, NAR-NGE-NPs improved the photostability and conferred protection against the NAR and NGE degradation. Stability studies of NAR-NGENPs demonstrated that only the suspension stored at $60^{\circ} \mathrm{C}$ did not show good stability. MIC of NAR and NGE were assessed and they did not show antimicrobial activity.

\section{Conflict of interest}

The authors declare no conflicts of interest.

\section{References}

1.Sayre CL, Gerde KD, Yáñez JA, Davies NM. Clinical Pharmacokinetics of Flavonoids. In Flavonoid Pharmacokinetics: Methods of Analysis, Preclinical and Clinical Pharmacokinetics, Safety and Toxicology, 1st Eds.; John Wiley \& Sons, Inc. Hoboken., USA, 2012; pp. 195-247.

2.Badarya OA, Abdel-Maksoudb S, Ahmedd WA, Owieda GH. Naringenin attenuates cisplatin nephrotoxicity in rats. Life Sciences 2005, 76, 2125-35.

3.Ghasemzadeh A, Jaafar HZ, Rahmat A. Antioxidant Activities, Total Phenolics and Flavonoids Content in Two Varieties of Malaysia Young Ginger (Zingiber officinale Roscoe). Molecules 2010, 15, 4324-33.

4.Liu Q, Lu L, Xião M. Cell surface engineering of a-Lrhamnosidase for naringin hydrolysis. Bioresour Technol 2012, 123, 144-49.

5.Kandhare AD, Raygude KS, Ghosh PA, Ghule E, Bodhankar SL. Neuroprotective effect of naringin by modulation of endogenous biomarkers in streptozotocin induced painful diabetic neuropathy. Fitoterapia 2012, $83,650-59$.

6.Choi JS, Yokozawa T, Oura H. Improvement of hyperglycemia and hyperlipemia in streptozotocindiabetic rats by a methanolic extract of Prunus davidiana stems and its main component, pruning. Planta Med 1991, 57, 208-11.

7.Mulvihill EE, Assini JM, Sutherland BG, DiMattia A, Khami M, Koppes JB, Sawyez CG, Whitman SC, Huff MW. Naringenin decreases progression of atherosclerosis by improving dyslipidemia in high-fatfed low-density lipoprotein receptor-null mice. Arterioscler Thromb Vasc Biol 2010, 30, 742-48.
8.Lee SM, Lee JH, Bae YC. Swelling behaviors of poly (methyl methacrylate) nano-sized gels in PEG/alcohol solutions. Fluid Phase Equilib 2014, 382, 107-15.

9.Semalty A, Semalty M, Singh D, Rawat MSM. Preparation and characterization of phospholipid complexes of naringenin for effective drug delivery. $\mathbf{J}$ Inclusion Phenom Macrocyclic Chem 2010, 67, 25360 .

10.Ameer B, Weintraub RA, Johnson JV, Yost RA, Rouseff RL. Flavanone absorption after naringin, hesperidin, and citrus administration. Clin Pharmacol Ther 1996, 60, 34-40.

11.Munin A, Edwards-Lévy F. Encapsulation of Natural Polyphenolic Compounds, a Review. Pharmaceutics 2011, 3, 793-829.

12.Vauthier C, Bouchemal K. Methods for the Preparation and Manufacture of Polymeric Nanoparticles. Pharm Res 2009, 26,1025-58.

13.Nollenberger K. Poly (meth) acrylate-based coatings. Int J Pharm 2013, 457, 461-69.

14.Fessi HPFD, Puisieux F, Devissaguet JP, Ammoury N, Benita S. Nanocapsule formation by interfacial polymer deposition following solvent displacement. Int J Pharm 1989, 22, R1-4.

15.Cordenonsi LM; Bromberger NG, Raffin RP, Scherman EE. Simultaneous separation and sensitive detection of naringin and naringenin in nanoparticles by chromatographic method indicating stability and photodegradation kinetics. Biomed Chromatogr 2016, 30, 155-162.

16.Nudelman NS. Estabilidad de medicamentos, 1st ed., Buenos Aires: El Atheneo, 1975.

17.Carstensen JT, Rhodes CT. Drug Stability: Principles and Practices, 3rd ed., Nova York: Marcel Dekker, 2000 .

18.CLSI - Clinical and Laboratory Standards Institute. Methods for dilution antimicrobial susceptibility tests for bacteria that grow aerobically, 6th ed., Wayne: Approved Standard, 2008.

19.Birnbaum DT, Kosmala JD, Henthorn DB, BrannonPeppas L. Controlled release of $\beta$-estradiol from PLAGA microparticles: The effect of organic phase solvent on encapsulation and release. J. Controlled Release 2000, 65, 375-87.

20.Peltonen L, Koistinen P, Karjalainen M, Häkkinen A, Hirvonen J. The effect of cosolvents on the formulation of nanoparticles from low-molecular- 
weight poly (I) lactide. AAPS Pharm Sci Tech 2002, 3. 52-8.

21.Song KC, Lee HS, Choung IY, Cho KI, Ahn Y, Choi EJ. The effect of type of organic phase solvents on the particle size of poly (d, 1-lactide-co-glycolide) nanoparticles. Colloids Surf A 2006, 276, 162-67.

22.Camili ST, Buyukserin F, Balci O, Budak GG. Size controlled synthesis of sub-100 $\mathrm{nm}$ monodisperse poly(methylmethacrylate) nanoparticles using surfactant-free emulsion polymerization. J. Colloid Interface Sci 2010, 344. 528-32.

23. Haznedar S, Dortunc B. Preparation and in vitro evaluation of Eudragit microspheres containing acetazolamide. Int J Pharm 2004, 269,131-40.

24.Hoffart V, Ubrich N, Simonin C, Babak V, Vigneron C, Hoffman M, Lecompte T, Maincent P. Low molecular weight heparinloaded polymeric nanoparticles: formulation, characterisation, and release characteristics. Drug Dev Ind Pharm 2002, 28, 1091-99.

25.Galindo-Rodrigues S, Allémann E, Fessi H, Doelker E. Physicochemical Parameters Associated with Nanoparticle Formation in the Salting-out, Emulsification-Diffusion and Nanoprecipitation Methods. Pharm Res 2004, 21, 1428-39.

26.Couvreur P, Barratt G, Fattal E, Legrand P, Vauthier C. Nanocapsule technology: a review. Crit Rev Ther Drug Carrier Syst 2002, 19, 99-134.

27.Moghimi SM, Hunter AC, Murray JC. Longcirculating and target-specific nanoparticles: theory to practice. Pharmacol Rev 2001, 53, 283-318.

28.Williams DB, Carter CB. The Transmission Electron Microscope, 1st ed., USA: Springer, 1996.

29.Pavia DL, Lampman GM, Kriz GS. Introduction to Spectroscopy: a guide for students of organic chemistry, 3 th ed., South Melbourme: Brooks/Cole, 2001.

30.Yu L. Amorphous pharmaceutical solids: preparation, characterization and stabilization. Adv Drug Delivery Rev 2001, 48, 27-42.

31.Lauro MR, Simone F, Sansone F, Iannelli P, Aquino RP. Preparations and release characteristics of naringin and naringenin gastro-resistant microparticles by spray-drying. J. Drug Delivery Sci Technol 2007, 17, 119-24.

32.Sansone F, Picerno P, Mencherini T, Villecco F, D'ursi AM, Aquino RP, Lauro MR. Flavonoid microparticles by spray-drying: Influence of enhancers of the dissolution rate on properties and stability. J Food Eng 2001, 103, 188-96.

33. Yang L, Ma S, Zhou S, Chen W, Yuan M, Yin Y, Yang $\mathrm{X}$. Preparation and characterization of inclusion complexes of naringenin with b-cyclodextrin or its derivative. Carbohydr Polym 2013, 98, 861-69.

34.Malesuik MD, Gonçalves HML, Paim CS, Schapoval EES, Steppe M. LC: analysis of photodegradation kinetics of nitazoxanide in pharmaceutical formulations. J Chromatogr Sci 2009, 47, 745-48.

35.Hsu CH, Cui Z, Mumper RJ, Jay M. Preparation and characterization of coenzyme Q10-loaded PMMA nanoparticles by a new emulsification process based on microfluidization. Colloids Surf A. 2003, 4, 24-35.

36.Mora-Huertas CE, Fessi H, Elaissari A. Polymerbased nanocapsules for drug delivery. Int J Pharm 2010, 385, 113-42.

37.Pohlmann AR, Weiss V, Mertins O, da Silveira NP, Guterres SS. Spray-dried indomethacin-loaded polyester nanocapsules and nanospheres: development, stability evaluation and nanostructure models. Eur J Pharm Sci 2002, 16, 305-12.

38.Lepeltier E, Bourgaux C, Couvreur P Nanoprecipitation and the "Ouzo effect": Application to drug delivery devices. Adv Drug Delivery Rev 2014, 71, 86-97.

39.Zhu Z. Flash Nanoprecipitation: Prediction and Enhancement of Particle Stability via Drug Structure. Mol Pharmaceutics 2014, 11, 776-86.

40.Céliz G, Daz M, Audisi MC. Antibacterial activity of naringin derivatives against pathogenic strains. J Appl Microbiol 2011, 111, 731-38.

41.Vandeputte OM, Kiendrebeogo M, Rasamiravaka T, Stevigny C, Duez P, Rajaonson S, Diallo B, Mol A, Baucher M, Jaziri ME. The flavanone naringenin reduces the production of quorum sensing-controlled virulence factors in Pseudomonas aeruginosa PAO1. Microbiology 2011, 157, 2120-32. 